\title{
Análisis crítico del discurso: la prensa sensacionalista en contextos culturales colindantes. El caso de Ajá en Perú y La Cuarta en Chile ${ }^{1}$
}

\author{
Recibido: 09 de diciembre de 2010 \\ Aceptado: 30 mayo de 2011 \\ Publicado: 31 de octubre de 2011
}

Rodrigo Browne Sartori rodrigobrowne@uach.cl Julio Carvajal Rivera jcarvaja@uach.cl

Rocío Salinas Oyarzo salinasoyarzo@gmail.com (Universidad Austral de Chile)

Resumen: Los medios de comunicación social (MCS) son comprendidos como productores relevantes de imágenes, prejuicios y estereotipos que conforman una identidad y una visión sobre los discursos de la diferencia.

El presente artículo forma parte de un proyecto en Ciencias de la Información que investiga la construcción de la realidad intercultural, aplicado, en este caso, a los diarios nacionales Ajá en Perú y La Cuarta en Chile, periódicos de alta lectura en ambos países. Al mismo tiempo, este estudio permite observar la percepción de la otredad, la autoimagen y, en consecuencia, el desarrollo del periodismo intercultural.

El objetivo de estos trabajos interculturales en el campo de la comunicación y el periodismo es, en definitiva, tender puentes entre las culturas, siendo su ejercicio una oportunidad de identificar la diversidad, que nos llevaría a un respeto hacia ellas y a un entendimiento intercultural más acabado.

Palabras clave: Periodismo intercultural, identidad, discurso, diferencia.

Abstract: Social communication media are understood as relevant producers of images, prejudices and stereotypes that make up a vision and identity about speeches on difference.

This article is part of a project on information science, and investigates how intercultural

1.- Este artículo forma parte del Proyecto Fondecyt $N^{\circ} 1100264$ titulado "Periodismo intercultural: Construcción de la noticia a través de un análisis crítico y complejo del discurso en la prensa diaria de cobertura nacional de Chile y Perú". 
reality is carried out. In this case, this is applied to the local newspapers Ajá (Perú) and La Cuarta (Chile) which are highly read in both countries. At the same time, this study allows to observe how otherness and self image are perceived, and as a consequence, the development of intercultural journalism.

The goal of these intercultural studies in the area of Communication and Journalism is definitely to set bridges among cultures, and it creates the opportunity of identifying diversity which would lead us to a better intercultural understanding and respect.

Key words: Intercultural Journalism, Identity, Discourse, Difference.

\section{Introducción}

Rodrigo Alsina (1999 y 2001) señala que, de acuerdo con las nuevas tecnologías de la información y comunicación (NTIC), tanto la representación de la realidad como las formas de comunicarse, varían su definición y su sentido, de tal manera que amplían sus horizontes.

Por tanto, la construcción de la identidad cultural debe adecuarse a los medios, dirigiendo su camino hacia la comunicación intercultural y, en consecuencia, al periodismo intercultural (Israel Garzón, 2004). Según estos conceptos, las personas reciben la información, construyen imágenes y montan visiones de lo identitario-alterno. Asimismo, las perspectivas que los individuos forman hacia su cultura y la de los demás varían de acuerdo con lo que ven.

Desde esta perspectiva, la mencionada autora (2002) hace referencia a la sensibilidad y tolerancia que deben tener los medios de comunicación para abordar contenidos interculturales al informar a los demás y, al mismo tiempo, cómo representar a las minorías sociales; es decir, hacer una construcción de la otredad y cómo estas repercuten en nuestras concepciones, sin dejar de lado la globalización mediática junto con la construcción de la identidad que provocan los medios. Reafirma Israel Garzón que, en el proceso de construcción noticiosa, la comunicación y periodismo intercultural deben ser abordados con el fin de manifestar transparencia, tolerancia y respeto ante otras culturas, sexos y razas.

En la presente investigación, se realiza un análisis crítico del discurso para observar cómo en dos tabloides (Ajá de Perú y La Cuarta de Chile) se realiza la práctica del periodismo sensacionalista, con motivo de analizar y comparar las relaciones y representaciones culturales plasmadas en sus páginas. De esta manera, se concluirá si ambos medios promueven, o no, prejuicios y estereotipos respecto a otras culturas.

\section{Construcción de la realidad noticiosa}

En 1972, desde la sociología, Berger y Luckmann estudiaron la construcción social de la realidad, entendiéndola como "una cualidad propia de los fenómenos que reconocemos como independientes de nuestra propia volición" (1972: 13). Ambos conciben la 
construcción de la realidad desde la práctica social, señalando que, para estudiar la realidad, se debe estudiar a los integrantes de una sociedad.

Los mencionados autores examinan la sociología del conocimiento, entendiendo esta como el procedimiento histórico-social que instaura los contenidos ideacionales del pensamiento humano, donde la corriente acerca de la conciencia del hombre (desde sus inicios) se ha determinado por el factor social, involucrando posteriormente el trasfondo intelectual y la atmósfera que lo rodea.

Los autores razonan desde la sociología del conocimiento y estudian la sociedad como realidad. Del mismo modo, señalan que el estar en una sociedad (incluirse en ella) es participar en su dialéctica. La comunicación es de vital importancia, puesto que el conocimiento y la experiencia construyen la identidad.

A pesar de esto, el individuo no nace miembro de una sociedad, sino que dentro del transcurso del tiempo se asocia y se incluye en ella. Lo importante es, más bien, el carácter intencional común del subconsciente o cómo las ideas de uno pueden afectar a otra realidad a través de la interacción social en la vida cotidiana.

Berger y Luckmann (1972) mencionan que esta información de la realidad se inserta en la conciencia a través de las rutinas, las cuales crean la naturaleza de la institucionalización. De ahí se entablan las teorías de la identidad, esta última formada por los procesos sociales. Una vez habituada, puede ser modificada, alterada, influida, producto de las relaciones sociales. Es por esto que las realidades subjetivas pueden variar o transformarse.

Indicado esto, podemos entender el proceso de socialización (exitosa), tal como señalan Berger y Luckmann, como la concordancia entre la realidad objetiva y subjetiva, la cual, a su vez, se puede manipular o alterar.

Rodrigo Alsina (2000), al igual que los sociólogos antes mencionados, concuerda que la identidad es construida mediante un proceso de socialización. Este autor concluye que dentro de la construcción social de la realidad de Berger y Luckmann, concibe "la construcción de la noticia como un tipo especial de realidad: la realidad pública" (Rodrigo Alsina, 1993: 15), refiriéndose al proceso de construcción noticiosa, la circulación y el consumo, es decir, cómo los periodistas crean la realidad pública.

Para esto, propone la siguiente definición de noticia: "representación social de la realidad cotidiana producida institucionalmente que se manifiesta en la construcción" (Rodrigo Alsina, 1993: 18). Asimismo, para referirse a la noticia como construcción social, concluye que el proceso de construcción de la realidad social se cumple, de manera correcta, a través de la práctica del periodismo.

\section{Comunicación intercultural}

Nace de la compleja realidad en la que vivimos día a día, desde principios del siglo XX. El desarrollo de las NTIC, los transportes, las industrias, la globalización, encaminan la 
mixtura de culturas, cada vez más común que en otros tiempos, motivo por el cual se hace necesario comprender al otro, como base para mantener una comunicación efectiva en el complejo mundo actual.

El interés por saber más acerca de la comunicación con otras culturas se vio incrementado por la creación de la Sociedad de Naciones (1920) y de la Organización de las Naciones Unidas (1945), entre otros organismos internacionales, que pusieron en el tapete la urgencia de una comunicación intercultural.

Para Casmir y Asunción-Lande (1989), la comunicación intercultural trata de comprender qué es lo que sucede cuando las diferentes culturas interactúan. En cambio Rodrigo Alsina la define como: "comunicación entre aquellas personas que poseen unos referentes culturales tan distintos que se autoperciben como pertenecientes a culturas diferentes" (1999: 12).

A consecuencia de lo antes mencionado, podemos comprender y resumir lo siguiente: la comunicación intercultural se produce cuando dos o más culturas interactúan, con la necesidad de una o de ambas partes. Simultáneamente, al despertar conciencia sobre la inmensa diversidad que existe en el mundo, se revela la urgencia de una comunicación entre varias culturas. Para esto surge el denominado "periodismo intercultural"2.

\section{Periodismo intercultural}

Bhabha (2002) establece un punto interesante en el ámbito intercultural, ya que se refiere a la hegemonía y a la creación de estereotipos que generan unas personas sobre otras; el choque de culturas entre los discursos de la diferencia ${ }^{3}$ que se produce cuando no existe la tolerancia a la cual apela Israel Garzón. Para esta autora, el periodismo intercultural intenta reconocer las diferentes idiosincrasias, respetándolas e incluyéndolas. Por esta razón, los medios de comunicación y periodistas (principales constructores de las imágenes que conforman una identidad y una visión sobre lo alterno) deben transmitir de manera abierta y tolerante para no caer en estereotipos ni eufemismos. Asombrosamente, estas construcciones (que se hacen llamar "informativas") muchas veces se escapan de esta realidad, generando y fundamentándose solo en prejuicios que buscan los choques y conflictos entre culturas. Es por esto que la labor del periodismo, en ámbitos de comunicación intercultural, es primordial.

Cuando no percibimos al otro tal y como es, contextualizado con su identidad cultural, e intentamos imponerle nuestras ideas, creencias, valores, actitudes, pautas de comportamiento, lengua, distorsionamos variables que constituyen su ser en el mundo (Israel Garzón, 2004).

2.- Este tipo de periodismo abarca temas interculturales de manera abierta y poco caprichosa; enseña a realizar la labor periodística sin caer en prejuicios ni estereotipos. Según Israel Garzón (2002 y 2004) los códigos éticos, la educación y la diversidad social asientan a la interculturalidad y así al periodismo intercultural.

3.- "El sujeto del discurso de la diferencia cultural es dialógico o transferencial, al modo del psicoanálisis [...] nunca es pura u holística sino que siempre está constituida en un proceso de sustitución, desplazamiento o proyección" (Bhabha, 2002: 199). 
La autora señala que es tarea de los medios de comunicación integrar y comprender las realidades exhaustivamente, adquiriendo importancia el tema de la responsabilidad social y la ética periodística. Para la autora, los MCS en nuestros países, por lo general, no son un buen ejemplo de periodismo intercultural, partiendo del hecho que no existe prácticamente un desarrollo en su agenda setting y, por ende, los hechos noticiosos relacionados a ello son mostrados generalmente en la "crónica roja", donde los inmigrantes son especialmente feos, ladrones, traficantes, entre otros rasgos.

Asimismo, aparecen los "ruidos interculturales", grietas que rompen la estructura de la comunicación y del periodismo intercultural, acarreando como consecuencias la creación de realidades estereotipadas referentes a grupos minoritarios.

¿Acaso estamos presenciando, como algunos pretenden, un lamentable choque de civilizaciones que sólo puede solucionarse permaneciendo cada uno en su lugar de origen? ¿Será inevitable la xenofobia, la discriminación, la guerra entre sociedades y culturas? ¿Estaremos ante una característica genética de la humanidad? (Grimson, 2000: 14).

El objetivo de estos estudios interculturales en la comunicación y el periodismo es, en definitiva, tender puentes entre las culturas, siendo su ejercicio una oportunidad de identificar la diversidad, que nos llevaría a un respeto hacia ellas y a un entendimiento intercultural más acabado.

Como disciplina, la comunicación intercultural es importante en actividades de lo cotidiano, ya sea para el desarrollo de la educación, la expansión de mercados, de los medios de comunicación, del desarrollo personal, entre otros. Siempre y cuando se espere una comunicación efectiva y comprensiva o flexible entre dos o más culturas.

Israel Garzón (2004) señala que la diferencia no obstaculiza sino que enriquece. Silva y Browne (2007) concuerdan con ella, apelan a asimilar otras culturas. Así, resulta de vital importancia estudiar la comunicación como un proceso de mixtura, sin fronteras que bloqueen nuestras ideas y pensamientos: abrir puertas sin cerrar otras.

En consecuencia, tanto Israel Garzón (2004), Bhabha (2002), como Silva y Browne (2007), apuntan hacia el respeto a la diversidad cultural, definiendo esta última como "la red de relaciones, sin jerarquías, homogeneidades, ni camino preestablecido, sino como líneas múltiples de culturas que se relacionan abiertamente con las otredades" (Silva y Browne, 2007: 34).

\section{Responsabilidad y producción de la realidad social}

A medida que se fue estudiando la profesionalidad periodística, no sólo se planteó la falta de objetividad, sino simultáneamente la manipulación de la información.

Israel Garzón propone un estudio por categorías que permitan una mejor observación a partir del género, edad, clase social, discapacidad, orientación sexual, apariencia física, 
religión, enfermedad, etnia, origen, entre otras, que sean las más utilizadas en los medios de comunicación, puesto que operan bajo una estrategia tradicional que enfatiza la transmisión del terror y el impacto, además de excluir a las minorías sociales. Estas rutinas, en el quehacer periodístico, van formando una construcción distorsionada y tendenciosa (por no decir pobre) de todas las posibilidades que el mundo social nos puede entregar para ser comunicadas. Así, podemos darnos cuenta cómo los prejuicios, estereotipos y el racismo forman parte de lo cotidiano.

Van Dijk (2001, 2002) señala que, al igual que los rumores, los estereotipos y los prejuicios étnicos se expanden velozmente. Lo mismo ocurre con el racismo ${ }^{4}$.

La gran variedad de discursos racistas en la sociedad, no sólo refleja representaciones sociales subyacentes variables, sino especialmente se adaptan a diversos contextos productivos: quién dice qué, dónde, cuándo, y con qué objetivos (Van Dijk, 2001; 2002: 195-196)

Conforme a que una de las más grandes mareas de información sobre diversas culturas llega a través de los MCS (creando imágenes mentales recurrentes) es necesario un análisis que identifique aquellos ruidos y buscar otros senderos que den paso al respeto y tolerancia. De esta manera, se obtendrá un mayor intercambio cultural en un mundo donde estos son cada vez más recurrentes y necesarios.

Es en casos como estos donde se pone a prueba la responsabilidad de la labor periodística, encargada de promover un entendimiento fructífero entre culturas cercanas, pero que hasta ahora solo contribuyen a explicitar características negativas muy bien asentadas en la opinión pública.

Por tanto, es tarea de los medios de comunicación integrar y comprender las realidades exhaustivamente, evidenciándose así la responsabilidad social y la ética del periodista.

Los medios deben evitar todo lo que resulte ofensivo para las minorías étnicas o religiosas. Deben ser pluralistas y reflejar la diversidad de la sociedad, concediendo acceso a los distintos puntos de vista y al derecho de réplica (Israel Garzón, 2002).

\section{Análisis crítico del discurso}

Se puede afirmar que en los titulares de la prensa escrita se manifiesta la realidad intercultural de la cual vivimos, donde aparecen los apodos, denominaciones, muestras de eufemismos o estereotipos. Para Van Dijk, en los medios de comunicación se puede apreciar la falta del valor periodístico, reflejado en los intereses económicos e ideologías.

En lo que se refiere al análisis crítico del discurso (ACD), el mencionado autor lo define como una especie de investigación exhaustiva o desglose de términos, que estudia tanto el texto, como el habla de los discursos en todas las perspectivas posibles. Estos se pueden

4.- "Se entiende como un sistema social complejo de dominación fundamentado étnica o racialmente" (Van Dijk, 2001; 2002: 192) 
aplicar al discurso periodístico, principalmente para descubrir el abuso del poder social y cómo la desigualdad es practicada junto a la hegemonía.

Según Berger y Luckmann, el individuo no nace miembro de una sociedad, sino que dentro del transcurso del tiempo se asocia a ella. Para Van Dijk (2001, 2002), el discurso actúa de la misma manera: al igual que el individuo se desarrolla dentro de la sociedad, el discurso cambia de acuerdo con las experiencias e interacciones y así este puede intervenir en la práctica discriminatoria.

Los prejuicios e ideologías étnicas no son innatos, y no se desarrollan espontáneamente en la interacción étnica. Se adquieren y se aprenden, y este sucede generalmente a través de la comunicación, es decir, a través del texto y la charla (Van Dijk, 2001; 2002: 192).

El autor resalta que el ACD, se centra en observar el ejercicio de poder y control del discurso, específicamente sobre los grupos y las instituciones. En conjunto, se puede afirmar que al comprender el discurso, se aprehenden los imaginarios colectivos, provocando (en cierta medida) el dominio y la hegemonía. En ese sentido, el ACD aparece como herramienta para dilucidar los conflictos ocultos (sociales o políticos) que los dominantes ejercen sobre una sociedad que vive fantaseando en su democracia.

El ACD actúa como herramienta metodológica cualitativa hermenéutica, para así comprender los procesos de representación de la realidad a través de las construcciones noticiosas y, además, el tratamiento que estas realizan en relación a los discursos de la diferencia, en este caso, chileno-peruano.

Paralelo a ese esquema, seguiremos varios ciclos de análisis, en este caso, una propuesta teórica-metodológica sugerida por Browne, Silva e Inzunza, tres investigadores pertenecientes al proyecto de origen, como matriz basada en el reseñado ACD de Van Dijk.

Para comprender los procesos de producción noticiosa y representaciones sociales dentro de Ajá y La Cuarta, se aplicará el ACD de forma deductiva, de lo general a lo particular (global-local), así como para identificar aspectos formales y de significado (Van Dijk, 2003), a través de dos planos y cuatro niveles:

Figura 1: Matriz del análisis crítico del discurso.

\begin{tabular}{l|l} 
6.1. Plano significado / texto & $\begin{array}{l}\text { 6.1.1. Nivel temático: significados globales. } \\
\text { 6.1.2. Nivel de significados locales. } \\
\bullet \text { De carácter implícito o indirecto. } \\
\text { D De carácter explícito o directo. }\end{array}$ \\
\hline 6.2. Plano formal / texto-contexto & $\begin{array}{l}\text { 6.2.1. Estructuras formales sutiles. } \\
\text { 6.2.2. Nivel contextual. }\end{array}$
\end{tabular}




\subsection{Plano significado / texto}

\subsubsection{Nivel temático: significados globales}

Se hace referencia principalmente a los temas que abarca el discurso periodístico analizado. Por lo general, no son reconocidos con tanta evidencia, sino que deben ser deducidos por el mismo discurso o asignados a él. A partir de este nivel se pueden deducir algunos modelos mentales del discurso analizado.

\subsubsection{Nivel de significados locales}

Se centra en la decodificación literal de las palabras. A diferencia de los significados globales, estos resultan de la concordancia que se realiza desde quienes emiten la noticia en relación a los modelos mentales establecidos, generando los estereotipos y/o prejuicios dentro de la información. Los significados locales se dividen en dos categorías:

- De carácter implícito o indirecto. Inquisiciones que se infieren de presupuestos, hipérboles, alusiones, ambigüedades, entre otros recursos. Son parte del modelo mental del público y no está evidentemente en el texto analizado. Por lo general, se evidencian indirectamente.

- De carácter explícito o directo. Son significados evidentes y se encuentran insertos con claridad en el discurso. Esta categoría permite identificar las palabras más utilizadas por los medios en determinadas informaciones, especialmente cuando se emiten prejuicios y palabras discriminatorias.

\subsection{Plano formal / texto-contexto}

\subsubsection{Estructuras formales sutiles}

Difunden modelos sesgados y no se perciben debido a la sutileza con la cual son empleados. Tienen como objetivo principal operar los aparatos ideológicos-formales del discurso (falacias, omisión de información crucial) obteniendo como resultado modelos sesgados e interesados de acuerdo con los "discursos de dominación" y sus respectivas fuentes. Arroja, de manera inconsciente, diferencias entre "lo mismo" (discurso de autoridad) y el "otro" (discurso de la diferencia).

\subsubsection{Nivel contextual}

Reúne las representaciones mentales de la memoria (a largo plazo). En resumen, lo que se recordará posteriormente, como modelo mental que se construye a través de lo emitido contextualmente en la construcción de la realidad (Berger y Luckmann, 1972) y su aproximación al periodismo en la construcción de la noticia (Rodrigo Alsina, 1999).

\section{Aplicación de la metodología}

Se tiene como objetos de estudio los tabloides La Cuarta y Ajá, los cuales difunden recurrentemente referencias de "lo chileno" y "lo peruano". El análisis abarcó todas las 
noticias publicadas entre el 6 de julio y el 6 de agosto de 2010 (debido a lo estipulado en el Proyecto Fondecyt $\left.N^{\circ} 1000264\right)$.

El proceso de selección consistió en la clasificación de todas las noticias de los diarios $L a$ Cuarta y Ajá que mencionaran aspectos o tópicos relacionados con el otro país (Ajá sobre "lo chileno" y La Cuarta sobre "lo peruano"). En total, se identificaron un total de 17 noticias: siete provenientes de Ajá y diez de su similar chileno.

\subsection{Percepción de "lo chileno" en Ajá}

Tras analizarse el texto titulado "Salud con Pisco" (figura 2), publicado en el tabloide peruano, se puede determinar lo siguiente:

\subsubsection{Plano significado / texto}

\subsubsection{Nivel temático: significados globales}

El gobierno peruano decretó que el cuarto domingo del mes de julio, será en Perú el "Día del Pisco". En el transcurso de la nota se desarrolla la discusión chileno-peruana sobre la procedencia de la mencionada bebida alcohólica, mezclándola además con el diferendo marítimo entre ambas patrias.

\subsubsection{Nivel de significados locales}

- De carácter implícito o indirecto. Se presenta a Chile confrontado con el Perú, debido a la procedencia del aguardiente de uva. Se enfatiza la figura de los chilenos como "transgresores" de la paternidad del pisco ("Poniendo en tela de juicio su origen peruano, como lo harán con la chirimoya, la papaya, y otros productos nativos, además de pretender quitarnos mar territorial"), así como "ladrones", que se atribuyen lo que no les corresponde. Por lo tanto, se deduce la hostilidad entre las naciones, más de la peruana hacia la chilena, como método de rencor por lo acontecido en referencia al pisco. Además, se emite un juicio subjetivo del redactor, afirmando que el pisco chileno "no es tan bueno como el nuestro, con todo respeto", que denota cargas de superioridad.

- De carácter explícito o directo. Se refuerza la idea de defender la procedencia peruana del pisco ("cultivado en la costa peruana hace cientos de años") ante la amenaza chilena ("se atribuían su paternidad"; "durante algunos años los chilenos no sólo marketeaban y exportaban"). 
Figura 2: Percepción de "lo chileno" en Ajá.

\section{Salud con pisco}

$>$ Asi como el pollo a la brasa, el cebic y otros platos representativos de rues gastronomla, nuestra bebida de banc ra, nuestio aguardiente de uva cultiva en la costa peruana desde hace cieni de años, no podia dejar de tener una cha recordatorla: el Goblemo decretó cuarto domingo de fulio como el Día! Pisco o sea que este ano se celebra howy se están juntando mi tó Koly Olcay con el $g$ do Acosta, que se las sabe todas.

> Y es que para disfrutarlo hay muchas, in chisimas maneras puro, en pisco sour, en Peru ubre, en chilcano Y lo bueno también es que nuestro pats ha welto a promocionar con éxito este trago y logrado introducito en todo el mundo, luego de quedurante algunos afios los th:lenos no solomarketeaban y exportaban pisco prodecido par ellos (que no es tan bueno como el nuestro. con todo respeto) sino que encima se atribulan su paterildad, poniendo en tela de juicio su origen penano

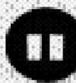

lamayork deperuanosvaa celebrar ese dia, ya seaensy casaoen diferentes baresy restauran tes. Esosi nadacle excesos". (como lo harian con la chirimoya, la papa yotros productos nativos, ad mas de pretender quitamos mar teriftorial).

> Mentras que a otros compatifotas nuestn como el escritor Marlo Vargas Llasa le resut banal la discusión sobre dónde nacló el ptsi (es decir, acư o más al sur), la mayoria de $p$ ruanos va a celebrar ese dia, va sea en su casa en diferentes bares y restaurantes. Eso ff, nas de excesos. El gordo Acosta va a salir sin car

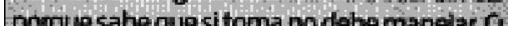

Fuente: Sección "La caserita" (Ajá, 25/VII/2010, p. 4).

\subsubsection{Plano formal / texto-contexto}

\subsubsection{Estructuras formales sutiles}

Se enfatiza que los chilenos "marketeaban y exportaban pisco producido por ellos", pese a que el Perú promociona también, a nivel mundial, la bebida. Asimismo, se subraya que el mérito es indudablemente del Perú y no compartido, a pesar de que ambos países exportan pisco. 
Si bien se hace mención de una posición conciliatoria (Mario Vargas Llosa, a quien "le resulta banal la discusión sobre dónde nació el pisco") el tono de confrontación y denuncia es predominante a lo largo del texto.

\subsubsection{Nivel contextual}

En suma, el texto resume la discusión entre los dos países sobre el origen del pisco, usando este tema como excusa para referirse al conflicto marítimo (que no tiene relación con el tópico principal) cambiándose el desenlace de la noticia, que en un principio estaba centrado en el Día del Pisco en el Perú y no sobre su naturaleza.

En ese sentido, se evidencian problemas históricos, económicos y sociales, sea por el diferendo marítimo entre las dos naciones, como por la discusión sobre la procedencia del pisco, denominado coloquialmente la "Guerra del Pisco", la cual (al igual que la Guerra del Pacífico) se genera por implicancias económicas.

\subsection{Percepción de "lo peruano" en La Cuarta}

Tras analizarse el texto titulado "Perú apoya salida al mar para Bolivia" (figura 3), publicado en el tabloide chileno, se puede determinar lo siguiente:

\subsubsection{Plano significado / texto}

\subsubsection{Nivel temático: significados globales}

La nota anuncia las declaraciones del canciller del Perú, quien manifiesta el apoyo de su nación ante una eventual solución a la salida al mar de Bolivia, en consecuencia al Tratado de 1929, el cual señala que en cualquiera de los casos Perú debe ratificar las decisiones tomadas por ambas naciones.

\subsubsection{Nivel de significados locales}

- De carácter implícito o indirecto. No se habla directamente de una salida al mar, sino de un "arreglo" para una salida al mar que beneficiaría a los altiplánicos. Puede ser lo mismo que hizo Perú con Bolivia, dar un paso, pero no ceder tierras.

- De carácter explícito o directo. Se denomina a José Antonio García Belaúnde como "canciller cholito", como recordatorio del color de la piel de la mayoría de los peruanos, pese a que el Ministro de Relaciones Exteriores es de tez blanca. Además se menciona que este personaje "juró que Perú no dará jugo para impedir que Chile y Bolivia arreglen una salida al mar". En el lenguaje coloquial chileno, dar jugo significa "contradecirse", "decir cosas incoherentes", "hacer cosas sin sentido", "generar problemas" o "perder el tiempo", por lo que se infiere que el gobierno peruano no se interpondrá en las negociaciones que puedan establecer Chile y Bolivia. 
Figura 3: Percepción de "lo peruano" en La Cuarta.

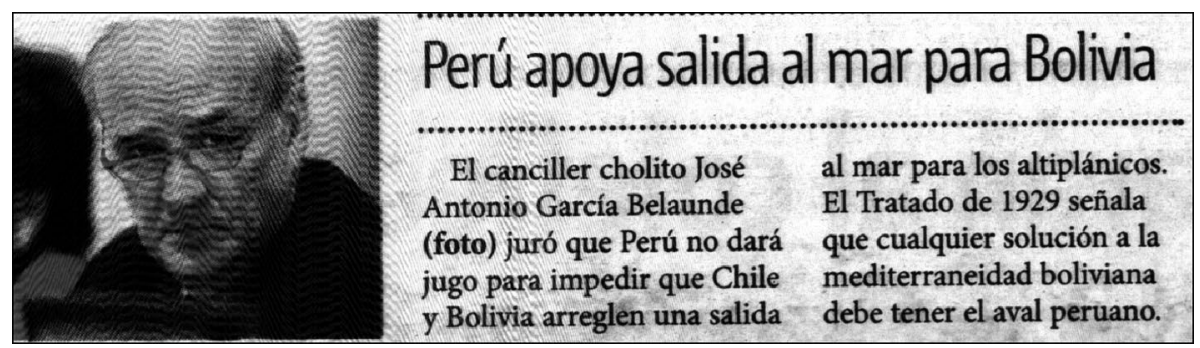

Fuente: Sección "La vuelta al mundo" (La Cuarta, 4/VIII/2010, p. 9).

\subsubsection{Plano formal / texto-contexto}

\subsubsection{Estructuras formales sutiles}

Se señala que Perú no obstruirá la idea de que Chile y Bolivia encuentren una solución en este problema, pero no se menciona que Perú apoya totalmente la salida al mar para Bolivia (salvo en el título).

\subsubsection{Nivel contextual}

Bolivia perdió ante Chile sus territorios costeros en la Guerra del Pacífico del siglo XIX, donde Perú también perdió algunas provincias. El Presidente Alan García y su par boliviano, Evo Morales, renovaron en el 2010 el acuerdo que concede al país altiplánico acceso al Océano Pacífico, otorgándosele además una zona franca industrial y económica (Ilo, Arequipa) por 99 años, fortificando sus lazos de amistad, los cuales fueron frágiles por diferencias ideológicas en años anteriores. Pese a esto, Chile aún no manifiesta evidencias de llegar a algún acuerdo.

\section{Resultados y conclusiones}

Se puede observar que de un total de 17 textos analizados (en este artículo tomamos sólo dos como ejemplos), un amplio porcentaje (52.3\%) de noticias hacen referencia al conflicto de la Guerra del Pacífico (1879-1883). Del mismo modo, sólo un texto del diario Ajá menciona, en concreto, el diferendo marítimo actual entre ambas naciones. A esto se le suma la polémica sobre la procedencia del pisco, la cual es señalada sólo en un texto perteneciente al periódico peruano. Asimismo, muchas de sus noticias acentúan las aparentes contradicciones económicas, sociales e ideológicas que existirían en Chile.

Por su parte, La Cuarta omite todo tipo de información respecto a la delimitación marítima con Perú, dedicándose a aludir la defensa de la tesis chilena (la cual sostiene que no existen temas fronterizos pendientes). Así, las noticias chilenas apuntan a enhebrar discursos de 
dominación sobre su vecino del norte. En suma, todo esto produce un choque de tendencias ideológicas y de los intereses de ambas naciones.

Respecto a los estereotipos encontrados, tanto La Cuarta como Ajá coinciden en varios aspectos. Ambos catalogan a sus vecinos como "agresivos", "exagerados", "conflictivos", "salvajes", "bravos", "peligrosos", "locos" y "violentos".

Debido al carácter sensacionalista de los diarios, se desprenden frases o palabras coloquiales, tales como la utilización de conceptos discriminatorios y diminutivos impuestos en la "memoria imaginaria" de cada uno:

- De peruanos hacia chilenos: rotos, mapochos, chilenitos.

- De chilenos hacia peruanos: incaicos, peruchos, cholitos, morenos.

En relación al nivel de significados locales (de carácter implícito o indirecto) el diario peruano Ajá principalmente se refiere a los chilenos como "alarmistas", "cobardes", "ladrones" y "exagerados", evidenciando un rechazo ante la otra nación. Mientras que el chileno La Cuarta representa a los peruanos como "ilegales", "pobres", "inmigrantes", "traficantes", "amenazadores"y "analfabetos", aludiendo a la discriminación que pesaría sobre los peruanos que radican en Chile, lo cual no ocurriría en el caso contrario, ya que nunca se menciona en el tabloide peruano la presencia de inmigrantes chilenos en su territorio.

Dentro del plano formal texto/contexto (en el nivel de estructuras formales sutiles) se pueden apreciar una serie de discursos de dominación y razonamientos de superioridad en ambas partes. Para expresar mejor lo antes mencionado, se detalla a continuación (figura 4) los calificativos y tratos manifestados:

Figura 4: Percepciones de "lo peruano" y "lo chileno" en La Cuarta y Ajá.

\section{LA CUARTA PERCIBE A LOS PERUANOS COMO:}

$A J A ́$ SE REFIERE A LOS CHILENOS COMO:

\section{PARA AMBOS \\ DIARIOS, EL UNO \\ Y EL OTRO SON:}

Ofensivos
Amparados
Discriminados
Irónicos
Pobres
Ilegales

Exagerados

Explotadores

Inventan cosas

Alarmados

Cobardes

Ladrones
Despectivos

Agresivos

Ideológicos

Amenazadores

Poco tolerantes

Beligerantes 
En los periódicos se exhiben imágenes despectivas de ambos países. Por un lado, los contenidos de Ajá (sobre todo los versados en el diferendo marítimo, la Guerra del Pacífico $\mathrm{u}$ otros temas sociopolíticos) son adversos a Chile y no le rescatan ninguna cualidad positiva. A modo de conveniencia ideológica, restan relevancia a noticias donde la imagen peruana podría verse afectada.

Por otro lado, el diario La Cuarta transmite un grado de superioridad hacia el Perú, aunque siempre imprimiendo el ambiente conflictivo y de competitividad entre ambas naciones (bajo la lógica que un país es mejor que el otro y siempre tiene que ganar). Este razonamiento se extendería también a Ajá.

Del mismo modo, ambos diarios degradan al "diferente": una cultura trata de abolir a la otra; ambas se atacan, ambas se miran "por sobre el hombro" y se ofenden como producto del ideal de superioridad. De esta forma, estas publicaciones generan un "círculo vicioso", poco transparente y tolerante, nutrido por la representación de estereotipos y juicios de valor sobre "lo alterno" y "lo propio".

Estos contenidos calan y se reafirman en el imaginario mental de los lectores, desarrollando un quiebre en las relaciones de diálogos interculturales y, por ende, provocando los "ruidos" (Israel Garzón, 2000) que limitan el intercambio entre culturas.

Asimismo, se demostró que, mediante el ACD, se puede realizar un análisis de la construcción social de la realidad intercultural y, por ende, del periodismo intercultural. En los MCS (en este caso enfocado en la prensa escrita) se traspasan imposiciones o cargas (sean imaginativas, moldeadas o ideológicas) por medio de sus publicaciones. Y aunque estas no siempre se puedan reconocer (ni menos interpretar) construyen nuestra manera de percibir la realidad y nuestra apreciación de otra cultura.

Muchas veces, los discursos periodísticos son creados de tal forma que omiten información crucial o expanden deliberadamente estereotipos, a fin de privilegiar sus respectivas ideologías e intereses. Es por esto que muchos de los autores y teóricos que estudian la comunicación y el periodismo intercultural hacen un llamado a los medios, periodistas y a la ciudadanía en general a tomar conciencia sobre lo leído, escuchado, visto e incluso aprendido en las mismas aulas de clases. Como se mencionó anteriormente, los estereotipos crecen y se reproducen tan rápido como los rumores.

En general, los MCS junto con los actores sociales (como transmisores de imágenes) no deben obstaculizar las relaciones entre culturas y sociedades, sino más bien cooperar en el intercambio y la integración. Es recomendable no caer en corrientes discriminatorias $\mathrm{y}$, por el contrario, crear conciencia de lo que se puede provocar, sobre todo ahora, que con el continuo avance de las redes de comunicación electrónica, no sólo un MCS, una empresa o un periodista tienen voz, sino que cualquier persona la tiene en la Internet. Por tanto, se deben aprovechar estos recursos, presentes en esta era mediática para establecer el intercambio positivo entre ambas culturas. 


\section{Fuentes consultadas}

Berger, P. L. y Luckmann, T. (1972). La construcción social de la realidad. Buenos Aires: Amorrortu.

Bhabha, H. (2002). El lugar en la cultura. Buenos Aires: Manantial.

Grimson, A. (2000). Interculturalidad y Comunicación. Buenos Aires: Norma.

Israel Garzón, E.

_(2004): “Comunicación intercultural y construcción periodística de la diferencia en la iniciativa de Comunicación”. Extraída el 10/IX/2011 desde http://www.comminit.com/la/node/149884

_(2002). "Comunicación intercultural para la formación de periodistas". Sala de prensa, 4(2).

Extraída el 10/IX/2011 desde http://www.saladeprensa.org/art378.htm

Rodrigo Alsina, M.

_(2001). "Medios de Comunicación e interculturalidad". Cuadernos de información, 14, 105-110. Extraída el 10/IX/2011 desde http://www.dialnet.unirioja.es/servlet/fichero articulo? codigo $=2938112 \&$ orden $=0$

(1999): Comunicación intercultural. Barcelona: Anthropos.

_(1993). La construcción de la noticia. Barcelona: Paidós.

Rodríguez Díaz, R. (2004): Teoría de la Agenda-Setting, aplicación a la enseñanza universitaria. Madrid: Observatorio Europeo de Tendencias Sociales.

Rodríguez González, R. (2003). "La Comunicación intercultural como base para una comunicación efectiva en las relaciones comerciales". Extraída el 10/IX/2011 desde http://www.psicologiacientifica. $\mathrm{com} / \mathrm{bv} /$ psicologia-210-1-la-comunicacion-intercultural-como-base-para-una-comunicacio.html\#

Silva, V. y Browne, R. (2007). Antropofagias. Las indisciplinas de la comunicación. Madrid: Biblioteca Nueva.

Van Dijk, T.

_(2003). La multidisciplinariedad del análisis critico del discurso: un alegato a favor de la diversidad. Métodos de análisis crítico del discurso. Barcelona: Gedisa.

_(2001/2002). Discurso y Racismo [Traducción del inglés por Christian Berger]. Instituto Latinoamericano de doctrina y estudios sociales ILADES - Universidad Alberto Hurtado, 14(3), 191-205.

_(1999). “El análisis crítico del discurso". Anthropos, 186, septiembre-octubre 1999, 23-36.

_(1994). “Discurso, poder y cognición social”. Cuadernos. 2(2).

_(1990). La noticia como discurso. Comprensión, estructura y producción de la información. Barcelona: Paidós. 